\title{
Motivation among Indonesian Nurses in Pursuing Continuing Professional Education and Its Relationship to Their Competencies
}

\author{
Fitriany Suangga ${ }^{1}$, Cyruz P. Tuppal $^{2}$ \\ ${ }^{1}$ Awal Bros Batam Health College, Riau Island, Indonesia \\ 2 St. Paul University Philippines System, Philippines; Tutor, Ministry of Health, \\ Muscat, Sultanate of Oman \\ Correspondending Author: Cyruz P. Tuppal (drcyruztuppal@gmail.com)
}

\begin{abstract}
Background: Nurses are required to maintain the standards of their practice through an informed range of Continuing Professional Education (CPE). However, there is a paucity of evidence exploring the relationship between motivation in pursuing $\mathrm{CPE}$ and competency among Indonesian nurses.

Purpose: This descriptive correlational study describes the motivation among Indonesian nurses in pursuing $\mathrm{CPE}$ and its relationship to their competency outcome performance.

Methods: Ninety-three staff nurses were chosen by convenience sampling, informed and gave consent for their voluntary participation in a selected hospital in Jakarta, Indonesia. Before the data collection, the researchers sought ethical clearance from the respective organizations. Eligible participants were those who have at least one-year hospital experience, naturally born Indonesian, and completed a degree in nursing. Data were collected using adapted, pilot-tested, translated, and validated sets of questionnaires.

Results: The findings revealed that most of the nurses were 21-30 years old, married, permanent employees with 1-3 years' working experience and had earned a degree in nursing. Indonesian nurses had moderate to high motivation in pursuing CPE and exemplified a fair to very good level of competency outcome performance. Results also indicated that among the motivation factors, expectancy was significantly associated with critical thinking $(r=0.259, p<0.012)$.

Conclusion: Motivation among Indonesian nurses in pursuing CPE was at a moderate to high level. As Indonesia emerges as a promising country, leaders need to increase the motivation of nurses in their pursuit of CPE. Highly competent and well-prepared nurses can facilitate a caring and healing environment for patients and contribute to the overall performance of health-care organizations and society.
\end{abstract}

Keywords: Competency; Continuing Professional Education (CPE); motivation; Indonesian nurses 


\section{BACKGROUND}

Hennessy, Hicks, Hilan, and Kawonal (2006) reported that "there is a serious shortfall of qualified nurses in Indonesia, with an estimated 50 nurses per 100.000 of the population" (p. 2). To address this issue, a focus on human resources for health must be tackled specifically on the nurses' expanding roles to meet the country's vision toward the development of a highly skilled and trained workforce. Indonesian nurses are required to maintain the standards of their practice through a diverse and informed range of continuing professional education (CPE). Nonetheless, there is a paucity of evidence that has explored nurses' motivation in pursuing CPE and its relationship to their competency.

The CPE is a crucial indicator for patients who depend on the nurse's up-to-date knowledge and skills (Chong, Sellick, Francis, \& Abdullah, 2011; Ni et al., 2014; Nsemo, John, Etifit, Mgbekem, \& Oyira, 2013; Pool, Poell, Berings, \& ten Cate, 2015; Pool, Poell, \& ten Cate, 2013). Nurses who are motivated to do well in CPE gain more knowledge and skills than less motivated nurses (Kemp \& Baker, 2013; Marzuki, Hassan, Wichaikhum, \& Nantsupawat, 2012; Pool et al., 2013). Apparently, those trained professionals and practitioners showed increased productivity, fewer occupational accidents, a higher level of work satisfaction, and effective patient outcomes.

Nurses become motivated to pursue CPE for various reasons. These reasons may be a mandatory requirement for registration and renewal or a desire to improve the standards of practice. Nurses are also motivated to experience new trends in nursing, increase their knowledge, enhance skills, cultivate career satisfaction, and for promotion (Brekelmans, Maassen, Poell, Weststrate, \& Geurdes, 2016). As the nursing practice in Indonesia continues to undergo radical changes and transformation, there is an urgent need for professionals to provide safe, effective, efficient, equitable, patient-centered, and quality health-care services (Hennessy et al., 2006). Nurses are the backbone of the health-care delivery system and serve as the key players in sustained and quality care. With this, organizations need to build a strong foundation of knowledge, skills, values, and attitudes threaded through the provision of CPE for nurses.

The CPE also provides a door for many opportunities to advance in the profession. Nurses who have achieved exemplary competence can be a medium of change. They would further understand various factors affecting the profession and develop strategic actions. Because the transition to professional practice is challenging, nurses need more mastery and advancement of knowledge about the profession, practice, and future priorities (Bindon, 2017). As explicated by Harper and Maloney (2017), nurses must position themselves to display their credence as it affirms the profession's worth. From a qualitative study among perioperative nurses, the findings indicate that through CPE, they gain acknowledgment from other professionals that contribute to their being assertive (Tame, 2013). Nurses further build a strong collegial partnership between and among members of the health-care team. As a result, it enhances a multidisciplinary milieu of trust, respect, and power. 
It has been mentioned that CPE contributes to the many facets of the nursing profession but would only be realized with a positive culture, effective partnership, and supportive learning environment. Hence, the motivation of nurses becomes important (Clark, Draper, \& Rogers, 2015). To make CPE effective, the design needs to address the current practice, anchored in partnerships with the stakeholders, foster a community of learning, and bring a significant impact to inform the practice (Clark et al., 2015). Proven in many other countries, investment in CPE programs at multiple levels contributes to the workforce development as evidenced by their skills and capabilities to respond effectively to the demands of the public whom they serve.

The Republic of Indonesia Law No. 23 Concerning Health (Indonesia, 1992) states that to implement quality health measures, the country needs to embrace the mandates to carry out or perform health activities in accordance with the areas of expertise and status of the relevant health authority. For this reason, more investment in the advancement of nurses' competence through CPE should be explored along with other factors that will motivate them. In this juncture, the researchers explored the motivation among Indonesian nurses in pursuing CPE and its relationships to their competency outcome performance, with an end view of proposing a training design program that aims to enhance the nurses' knowledge, elevate the standard of service delivery, and determine the essential competency required for a safe, effective, efficient, timely, and quality patient care.

\section{PURPOSE}

This study described the motivation among nurses in pursuing CPE and its relationship to their competency outcome performance.

\section{METHODS}

This study used a descriptive correlation research design that determined the relationship between motivation in pursuing $\mathrm{CPE}$ and the competency outcome performance among staff nurses in Indonesia. Prior to the data collection, administrative, institutional, ethical clearance, and permission to conduct this study were sought from the relevant organizations, including the hospital where data collection was conducted. Selected participants were informed and gave consent for their voluntary participation. Both rights to privacy and confidentiality were elicited prior to the questionnaire distribution. Eligible participants were given an option that if they want to discontinue their participation, they would be given their rights to selfdetermination. Ninety-three staff nurses were chosen by convenience sampling in a selected hospital in Jakarta, Indonesia. The nurses included in this study had at least one-year hospital experience in their current workplace, naturally born Indonesian, and had completed their nursing education.

The motivation of nurses was measured using a 30-item adapted questionnaire consisting of three categories (expectancy, valence, and instrumentality) (Ayres, 2005). The second questionnaire assessed the competency outcome performance using a 40item questionnaire based on the eight core indices adapted from the Competency Outcome Performance Assessment (COPA) Model (Lenburg, 1999). Both 
questionnaires were rated using a four-point Likert scale $(1.00=$ poor/not motivated, $2=$ fair/moderately motivated, $3.00=$ very good/highly motivated). The questionnaires were translated into Bahasa Indonesia and back-translated into English to ensure that the meaning, content, and syntax did not change. Experts validated the two questionnaires, and a pilot study was performed. The Cronbach alpha for the questionnaires revealed a high reliability of 0.95 for the motivation and 0.98 for the competency. To measure the relationships between nurses' motivation and competency, Spearman's rho was used.

\section{RESULTS}

\section{Demographic profile of staff nurses}

Table 1 shows that among the 93 participants, the highest percentage comes from the age group of $21-30$ years (76 or $81.7 \%$ ), were married (50 or $53.8 \%$ ), permanent employees (61 or $65.6 \%$ ), length of experience of $1-3$ years (45 or $48.4 \%$ ) and had a Bachelor's degree (87 or $93.5 \%$ ).

Table 1. Demographic profile of staff nurses

\begin{tabular}{lc}
\hline Demographic Profile & $\mathrm{n}(\%)$ \\
\hline Age & $76(81.7)$ \\
$21-30$ & $15(16.1)$ \\
$31-40$ & $2(2.2)$ \\
$41-50$ & \\
Marital Status & $43(46.2)$ \\
Single & $50(53.8)$ \\
Married & \\
Employment Status & $32(34.4)$ \\
Contract & $61(65.6)$ \\
Permanent & \\
Length of Clinical Experience & $15(16.1)$ \\
<1 & $45(48.4)$ \\
$1-3$ & $20(21.5)$ \\
4-6 & $13(14)$ \\
$>6$ & \\
Educational Attainment & $2(2.2)$ \\
SPK & $4(4.3)$ \\
Diploma & $87(93.5)$ \\
Bachelor &
\end{tabular}

\section{Motivation among Indonesian Nurses}

The motivation among nurses revealed a high level in pursuing continuing education specifically on expectancy (2.64), instrumentality (2.44) and valence (2.29).

Table 2. Motivation among Indonesian nurses

\begin{tabular}{lccc}
\hline Motivation & Mean & SD & Interpretation \\
\hline Expectancy & 2.64 & 0.49 & Highly Motivated \\
Instrumentality & 2.44 & 0.62 & Highly Motivated \\
Valence & 2.29 & 0.68 & Moderately Motivated \\
\hline
\end{tabular}




\section{Competency outcome performance assessment among nurses}

The findings showed that among the competency domains, nurses exemplified a high level of critical thinking (2.73), human caring/relationship skills (2.67), and leadership skills (2.66).

Table 3. Competency assessment domains among nurses

\begin{tabular}{lccc}
\hline Domains & Mean & SD & Interpretation \\
\hline Assessment and Intervention Skills & 2.37 & 0.45 & Very Good \\
Communication Skills & 2.36 & 0.49 & Very good \\
Critical Thinking & 2.73 & 0.45 & Very Good \\
Human Caring/Relationship Skills & 2.67 & 0.40 & Very Good \\
Teaching Skills & 2.54 & 0.52 & Very Good \\
Management Skills & 2.60 & 0.44 & Very Good \\
Leadership Skills & 2.66 & 0.39 & Very Good \\
Knowledge Integration Skills & 2.63 & 0.49 & Very Good \\
\hline
\end{tabular}

The relationship between the motivation in pursuing CPE and nurses' competencies

Among the competencies displayed by staff nurses, only critical thinking was significantly related to motivation, specifically on expectancy $(r=0.259, p<0.05)$.

Table 4. Relationship between motivation and competency domains

\begin{tabular}{lcccccc}
\hline \multirow{2}{*}{ Competency Domains } & \multicolumn{2}{c}{ Expectancy } & \multicolumn{2}{c}{ Instrumentality } & \multicolumn{2}{c}{ Valence } \\
\cline { 2 - 7 } & rs & Sig. & rs & Sig. & rs & Sig. \\
\hline Assessment and Integration & 0.141 & 0.169 & 0.04 & 0.721 & 0.08 & 0.473 \\
Communication & 0.141 & 0.177 & 0.05 & 0.641 & 0.02 & 0.847 \\
Critical Thinking & 0.259 & $0.012^{*}$ & 0.02 & 0.845 & 0.04 & 0.726 \\
Human Caring/Relationship skills & 0.052 & 0.621 & -0.01 & 0.939 & 0.13 & 0.213 \\
& & & & & & \\
Teaching Skills & -0.02 & 0.882 & -0.04 & 0.731 & -0.08 & 0.459 \\
Management Skills & 0.127 & 0.227 & -0.09 & 0.367 & -0.08 & 0.425 \\
Leadership Skills & -0.039 & 0.71 & 0.07 & 0.478 & 0.08 & 0.403 \\
Knowledge integration Skills & -0.018 & 0.857 & -0.09 & 0.387 & -0.2 & 0.059 \\
\hline Note: rs=Spearman rho, $* p<0.05$ & & & & & &
\end{tabular}

\section{DISCUSSION}

As the country currently experiences and faces a critical challenge in the supply of human resources for health, Indonesian nurses should strengthen and enhance their knowledge, skills, and attitudes through CPE (Kurniati, Rosskam, Afzal, Suryowinoto, $\&$ Mukti, 2015). Indonesia needs to review and develop a policy on a health-care workforce with government support, commitment, and multisectoral approach (Kurniati et al., 2015). A mismatch between production and demand, as well as the quality of the workforce, maldistribution, and compensation has been a challenge as well. From the report of the World Health Organization in 2006, Indonesia belongs to the 57 countries experiencing a shortage of human resources for health (Kurniati et al., 2015). Through a multistakeholder coordination, the process of identifying the problems and main areas of concern specifically on human resources has been established. Through this approach, it strengthens the quality production of resources for health, including human 
resources. Furthermore, it fosters scaling up of the educational preparation and continuing professional development of doctors, nurses, and other allied health practitioners and professionals.

In the Philippines, for example, the Philippine Regulation Commission (PRC) Resolution No. 38 Series of 1995 defined CPE as the "inculcation, assimilation, and acquisition of knowledge, skills, proficiency, and ethical and moral values after the initial registration of a professional that raise and enhance one's technical skills and professional competence"(Loretto, 1996, p. 79 cited in Joseph, 2011). CPE is an essential instrument for personal growth, professional development, advancement in the profession and for the well-being of the patients (Kovner, Brewer, Katigbak, Djukic, \& Fatehi, 2012; Pool, Poell, Berings, \& ten Cate, 2016). Participation in CPE is directly related to effective and efficient nursing practice because it enhances the clinical competence of nurses and other allied health practitioners (James \& Francis, 2011). Pool et al. (2015) stated that continuing education is crucial for the safety of the patients or clients who depend on the nurse's up-to-date knowledge and skills related to patient care management.

Nurses have different motivations in pursuing CPE. The findings of this study indicate that Indonesian nurses have a high level of motivation along with the three domains, namely expectancy, instrumentality, and valence. Participants highly rated the expectancy area which explains how nurses perceived the likelihood that their effort would help them to attain excellence in the clinical area. Expectancy involves an understanding that an increased effort leads to high performance, but the individual must have previous experience, necessary machinery, tools, and opportunity to perform. On nurse's instrumentality, it involves whether a successful performance will lead to the desired outcome. Vroom (1999) explained that if the instrumentality is high, the individual will be more highly motivated. He further posited that if the expectancy is low, it will not produce the desired outcome, and motivation will be less. The results also indicate that nurses displayed motivation at a moderate level regarding valence. This finding implies that staff nurses give moderate value to the outcomes that they will receive after attending a CPE program. Thus, nurses require an avenue that will facilitate them to apply what they have learned from the CPE. Despite nurses having a strong belief that knowledge, skills, and attitude are acquired through a continuing education program, Burrow, Mairs, Pusey, Bradshaw, and Keady (2016) suggested that the management should understand that motivation among nurses may also include personal and professional drivers, influence of workplace, funding, and availability of CPE.

In the Netherlands, 1226 registered nurses were sampled to identify the factors related to nurses undertaking CPE. Using a survey approach, Brekelmans et al. (2016) found that if nurses consider a CPE activity as relevant for their practice, the more likely they are to have the motivation to pursue it. This factor has been identified as a critical area to consider in the development of CPE programs. Brekelmans et al. (2016) surmised that nurses pursue CPE as a mandatory requirement, but some are involved due to participation in research, professional, and organizational development. 
Pool et al. (2016) found from a qualitative and exploratory design using a semistructured interview that nurses' engagement to continuing professional development is essential for better performance, skills, and competence enhancement. Pool et al. (2016) identified nine types of motives or purposes among nurses in pursuit of CPE, which include to (a) deepen the knowledge, enhance career development, comply with the requirement, supplement gaps in prior education, (b) increase self-esteem, (c) relief from clinical routines, (d) expand professional linkages and networks, (e) improve health care, and (f) increase competence in the present job.

Schumacher and Risco (2017) opined that competency is a cumulative set of the desired knowledge, skills, and behaviors through assimilation, acquisition, and embodiment. Competency enables one effectively to perform the activities of a given occupation or function to the standards expected in employment. Nurses' skills can be evaluated in multimodal approaches. This study used the COPA (Lenburg, 1999), which consisted of eight domains.

The COPA model provides an intensive process development of competence in nursing practice (Lenburg, 1999 cited in Klein \& Fowles, 2009). In this present study, nurses had fair to good results in the competency evaluation. The critical thinking was identified as the highest domain. This finding implies that nurses contribute to the decision-making and analytical capabilities of their patients' needs and concerns. Furthermore, nurses are expected to be competent in all domains of nursing practice that should be prioritized by any health-care organization (Klein \& Fowles, 2009). With this, the nursing organizations should be mandated to have a periodic competency assessment in conjunction with the diverse background of nurses (Franklin \& Melville, 2015).

Critical thinking is "the ability to apply higher-order cognitive skills (conceptualization, analysis, evaluation) and the disposition to be deliberate about thinking (being openminded or intellectually honest) leading to action that is logical and appropriate"(Papp et al. 2014, p. 716 cited in Von Colln-Appling \& Giuliano, 2017). However, critical thinking only becomes apparent when nursing graduates start to immerse as entry level nurses in the hospitals (Klein \& Fowles, 2009). Therefore, the practice should illuminate clinical strategies to enhance critical thinking abilities. With such abilities, nurses achieve an optimal performance and contribute to the better patient care and quality outcomes (Kaddoura, Van Dyke, \& Yang, 2017; Risling, 2017).

Motivation on expectancy was found to be significantly associated with critical thinking skills among Indonesian nurses. This finding implies that nurses are motivated to attend $\mathrm{CPE}$ in the hope that their skills will be strengthened, improved, and nurtured as they care for diverse patients. The results also suggest that nurses should also develop the foresight to anticipate either the actual or potential needs of their patients.

The researchers proposed a Training Program Design (Figure 1) that highlights the nurses' motivation and competency performance aiming to develop a holistic and integrative professional development. Undeniably, nurses serve as the backbone of the health-care delivery system, which should be provided with the highest level of support 
from the organizations and the government. Nurses help their patients to do what they would do for themselves if they could. Nurses provide a holistic person-centered care with tenderness, love, and care. Nurses always find a way to see if the patient is breathing correctly, visiting many times to see if they are all well-nourished, in comfort and happy, and assist in all possible ways.

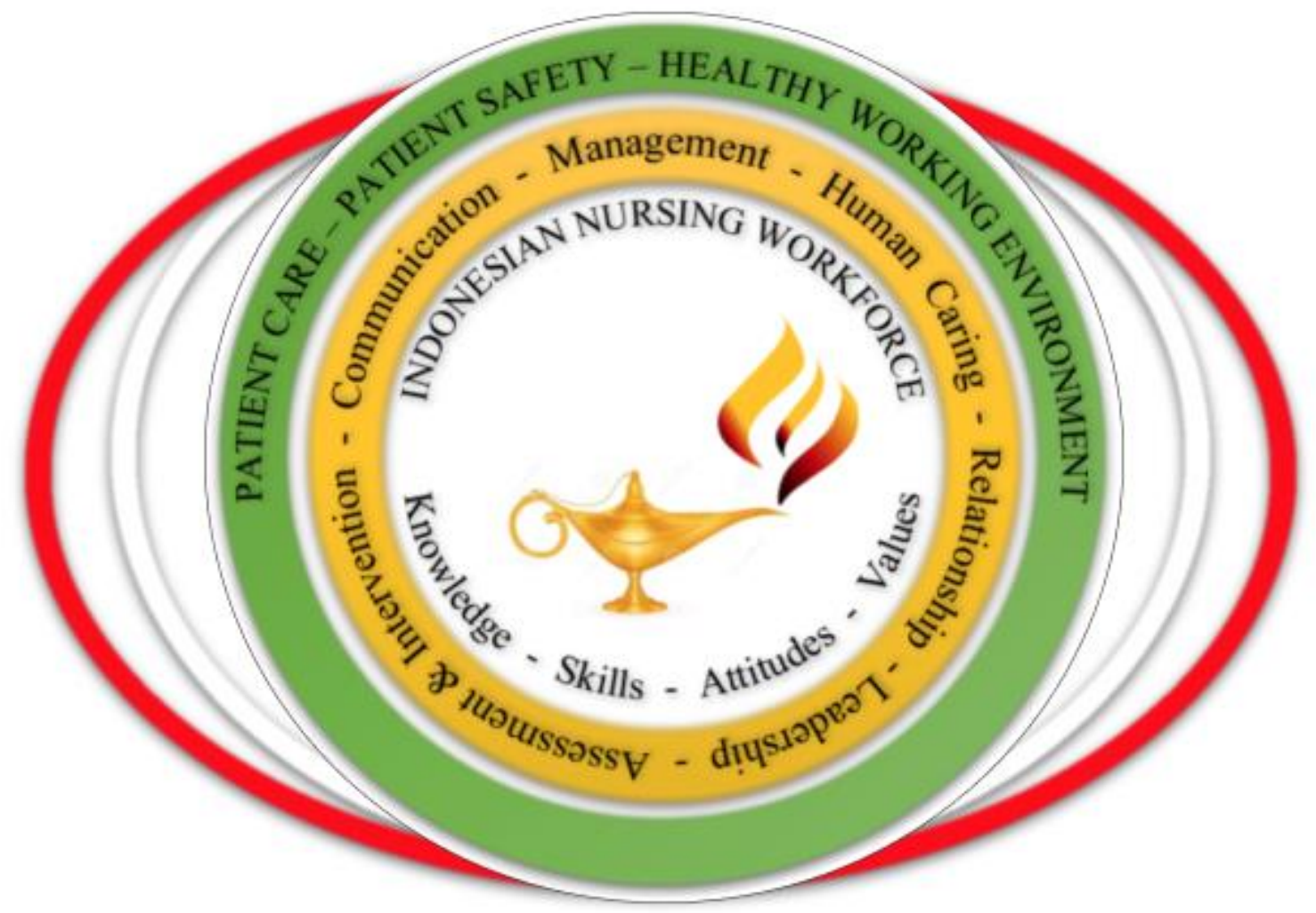

Figure 1. Training program design for nurses' continuing professional education

Despite nurses gaining a cadre of skills and competencies, human caring and interpersonal skills are also vital aspects. The proposed training program is not only intended for skills acquisition but also grounded in caring perspectives that remain as a fundamental concept in the practice of nursing. Through caring - the language of nursing - nurses can provide holistic care to their patients, families, and communities. This proposed training design needs a collaborative partnership between service and education to foster open communication in a dynamic and supportive learning environment. Furthermore, the CPE developers should identify both facilitators and inhibitors to sustain motivation among nurses. These facilitators and inhibitors are pivotal to making the program design more doable, feasible, and practical. Facilitators include but are not limited to the commitment of the management, alignment of personal and professional development to the organizational goals, readiness among nurses, appropriate course design, delivery, and evaluation (Clark et al., 2015). The inhibitors may include but are not limited to inflexibility, inadequate organization support to learning, different cultures, and various generational workforce needs (Clark et al., 2015). 
When synergism remains at the core of the nursing workforce, there is no doubt that the profession will continue to light its lamp to shed an enticing movement toward the improvement of patient care, provision of patient safety, and sustenance of a healthy working environment.

\section{CONCLUSION}

This study revealed that the motivation among Indonesian nurses in pursuing CPE was at a moderate to high level. The result of this study also indicated that among the motivation factors, expectancy was significantly associated with critical thinking. Indeed, Indonesia is an emerging country where nursing leaders are in a joint effort to elevate the morale of the discipline as well as the competency of nurses at multiple levels. Through their support in motivating many nurses in various settings, they are also helping the country to achieve its strategic vision in producing a highly skilled workforce. In addition, there is a need for straight forward policies to leverage workforce performance and productivity through transformative human resources training and development plans.

\section{REFERENCES}

Ayres, H. W. (2005). Factors related to motivation to learn and motivation to transfer learning in a nursing population. (Doctor of Education), North Carolina State University, United States of America. Available from ProQuest Dissertations and Theses.

Bindon, S. L. (2017). The next new grad. Journal for Nurses in Professional Development, 33(2), 55.

Brekelmans, G., Maassen, S., Poell, R., Weststrate, J., \& Geurdes, E. (2016). Factors influencing nurse participation in continuing professional development activities: Survey results from the Netherlands. Nurse Education Today, 40, 1319. doi:http://dx.doi.org/10.1016/j.nedt.2016.01.028

Burrow, S., Mairs, H., Pusey, H., Bradshaw, T., \& Keady, J. (2016). Continuing professional education: Motivations and experiences of health and social care professional's part-time study in higher education. A qualitative literature review. International Journal of Nursing Studies, 63, 139-145. doi:http://dx.doi.org/10.1016/j.ijnurstu.2016.08.011

Chong, M., Sellick, K., Francis, K., \& Abdullah, K. (2011). What influences Malaysian nurses to participate in continuing professional education activities? Asian Nursing Research, 5(1), 38-47. doi:http://dx.doi.org/10.1016/S19761317(11)60012-1

Clark, E., Draper, J., \& Rogers, J. (2015). Illuminating the process: Enhancing the impact of continuing professional education on practice. Nurse Education Today, 35(2), 388-394. doi:http://doi.org/10.1016/j.nedt.2014.10.014

Franklin, N., \& Melville, P. (2015). Competency assessment tools: An exploration of the pedagogical issues facing competency assessment for nurses in the clinical environment. Collegian, 22(1), 25-31. doi:http://doi.org/10.1016/j.colegn.2013.10.005 
Harper, M. G., \& Maloney, P. (2017). Our role as advocate for the nursing professional development specialty. Journal for Nurses in Professional Development, 33(2), 99-101.

Hennessy, D., Hicks, C., Hilan, A., \& Kawonal, Y. (2006). The training and development needs of nurses in Indonesia. Human Resources for Health, 4(1), 10. doi:http://10.1186/1478-4491-4-10

Indonesia. (1992). Republic of Indonesia Law No. 23 Concerning Health. Retrieved from http://www.ilo.org/

James, A., \& Francis, K. (2011). Mandatory continuing professional education: What is the prognosis? Collegian, 18(3), 131-136. doi:http://dx.doi.org/10.1016/j.colegn.2011.03.001

Joseph, P. V. (2011). Continuing professional education. In H. R. Feldman (Ed.), Nursing Leadership. New York: Springer Publishing Company.

Kaddoura, M. A., Van Dyke, O., \& Yang, Q. (2017). Correlation between critical thinking skills and national council licensure examination for registered nurses success in accelerated bachelor nursing students. Teaching and Learning in Nursing, 12(1), 3-7. doi:http://dx.doi.org/10.1016/j.teln.2016.08.004

Kemp, S., \& Baker, M. (2013). Continuing professional development - reflections from nursing and education. Nurse Education in Practice, 13(6), 541-545. doi:http://dx.doi.org/10.1016/j.nepr.2013.04.009

Klein, C. J., \& Fowles, E. R. (2009). An investigation of nursing competence and the competency outcomes performance assessment curricular approach: Senior students' self-reported perceptions. Journal of Professional Nursing, 25(2), 109121. doi:http://doi.org/10.1016/j.profnurs.2008.08.006

Kovner, C., Brewer, C., Katigbak, C., Djukic, M., \& Fatehi, F. (2012). Charting the course for nurses' achievement of higher education levels. Journal of Professional Nursing, 28(6), 333-343. doi:http://dx.doi.org/10.1016/j.profnurs.2012.04.021

Kurniati, A., Rosskam, E., Afzal, M. M., Suryowinoto, T. B., \& Mukti, A. G. (2015). Strengthening Indonesia's health workforce through partnerships. Public Health, 129(9), 1138-1149. doi:http://doi.org/10.1016/j.puhe.2015.04.012

Lenburg, C. (1999). The framework, concepts, and methods of the Competency Outcomes and Performance Assessment (COPA) model. Online Journal of Issues in Nursing. Retrieved from http://www.nursingworld.org/ojin/topic10/tpc10_2.htm

Marzuki, M. A., Hassan, H., Wichaikhum, O., \& Nantsupawat, R. (2012). Continuing nursing education: Best practice initiative in nursing practice environment. Procedia - Social and Behavioral Sciences, 60, 450-455. doi:http://dx.doi.org/10.1016/j.sbspro.2012.09.405

Ni, C., Hua, Y., Shao, P., Wallen, G., Xu, S., \& Li, L. (2014). Continuing education among Chinese nurses: A general hospital-based study. Nurse Education Today, 34(4), 592-597. doi:http://dx.doi.org/10.1016/j.nedt.2013.07.013

Nsemo, A., John, M., Etifit, R., Mgbekem, M., \& Oyira, E. (2013). Clinical nurses' perception of continuing professional education as a tool for quality service delivery in public hospitals Calabar, Cross River State, Nigeria. Nurse Education in Practice, $13(4), \quad 328-334$. doi:http://dx.doi.org/10.1016/j.nepr.2013.04.005 
Pool, I., Poell, R., Berings, M., \& ten Cate, O. (2015). Strategies for continuing professional development among younger, middle-aged, and older nurses: A biographical approach. International Journal of Nursing Studies, 52(5), 939950. doi:http://dx.doi.org/10.1016/j.ijnurstu.2015.02.004

Pool, I., Poell, R., Berings, M., \& ten Cate, O. (2016). Motives and activities for continuing professional development: An exploration of their relationships by integrating literature and interview data. Nurse Education Today, 38, 22-28. doi:http://doi.org/10.1016/j.nedt.2016.01.004

Pool, I., Poell, R., \& ten Cate, O. (2013). Nurses' and managers' perceptions of continuing professional development for older and younger nurses: A focus group study. International Journal of Nursing Studies, 50(1), 34-43. doi:http://dx.doi.org/10.1016/j.ijnurstu.2012.08.009

Risling, T. (2017). Educating the nurses of 2025: Technology trends of the next decade. Nurse Education in Practice, $22,99-92$. doi:http://dx.doi.org/10.1016/j.nepr.2016.12.007

Schumacher, G., \& Risco, K. (2017). Nurse practitioner program curriculum development: A Competency-based approach. The Journal for Nurse Practitioners, 13(2), 75-81. doi:http://dx.doi.org/10.1016/j.nurpra.2016.10.014

Tame, S. L. (2013). The effect of continuing professional education on perioperative nurses' relationships with medical staff: Findings from a qualitative study. Journal of Advanced Nursing, 69(4), 817-827. doi:10.1111/j.13652648.2012.06065.x

Von Colln-Appling, C., \& Giuliano, D. (2017). A concept analysis of critical thinking: A guide for nurse educators. Nurse Education Today, 49, 106-109. doi:http://dx.doi.org/10.1016/j.nedt.2016.11.007

Vroom, V. (1999). Work and motivation. San Francisco: Jossey-Bass. 